\title{
Disease Prevalence and Fatality, Life History Strategies, and Behavioral Control of the COVID Pandemic
}

\author{
Hui Jing Lu ${ }^{1} \cdot$ Xin Rui Wang ${ }^{2} \cdot$ Yuan Yuan $\mathrm{Liu}^{2} \cdot$ Lei Chang ${ }^{2}$ (1)
}

Received: 27 July 2021 / Revised: 18 October 2021 / Accepted: 18 October 2021 / Published online: 9 November 2021

(c) The Author(s), under exclusive licence to Springer Nature Switzerland AG 2021

\begin{abstract}
The COVID-19 pandemic caught the world by surprise and raised many questions. One of the questions is whether infectious diseases indeed drive fast life history $(\mathrm{LH})$ as the extent research suggests. This paper challenges this assumption and raises a different perspective. We argue that infectious diseases enact either slower or faster LH strategies and the related disease control behavior depending on disease severity. We tested and supported the theorization based on a sample of 662 adult residents drawn from all 32 provinces and administrative regions of mainland China. The findings help to broaden $\mathrm{LH}$ perspectives and to better understand unusual social phenomena arising from the COVID-19 pandemic.
\end{abstract}

Keywords COVID-19 pandemic $\cdot$ Fast and slow life history strategies $\cdot$ Intrinsic and extrinsic mortality $\cdot$ Prevalence and fatality of infectious diseases

\section{Introduction}

The ongoing coronavirus disease 2019 (COVID-19), a newly emerged respiratory disease caused by severe acute respiratory syndrome coronavirus 2 (SARS-CoV-2), has, by surprise, become one of the most serious public health crisis in modern human history (Syal, 2020). Equally unexpected is the humbling revelation that human advancement in science, and medicine has to date proven ineffective in preventing and intervening with the coronavirus. Until the recent commencement of vaccination that has covered only fractions of the world populations, the only effective prevention has been traditional behavioral methods such as hand washing, mask wearing, and social distancing (Anderson et al., 2020), all of which have been practiced by human ancestors (e.g., Conti \& Gensini, 2007) and, in the same or variant forms, have been used by other animals as well (Hart \& Hart, 2018). Even more unexpectedly, the highest infections and fatalities are found in developed and affluent countries such as the USA and Europe, where governments and populations also did not appear to

Lei Chang

chang@um.edu.mo

1 Department of Applied Social Sciences, The Hong Kong Polytechnic University, Kowloon, Hong Kong, China

2 Department of Psychology, Faculty of Social Sciences, University of Macau, Taipa, Macao, China be taking sufficient disease control actions especially at early stages of the pandemic (e.g., Shokoohi et al., 2020), whereas the pandemic has been relatively well managed in poor and developing countries in Africa and Asia, where behavioral control response has been more swift and vigilant (e.g., Rupiva, 2020; Shaw et al., 2020). An added surprise comes from the fact that both contemporary and historical pathogenic prevalence are much lower in Europe and North America where the COVID-19 pandemic has not been well controlled compared to Africa and Asia (Murray \& Schaller, 2009). These surprises in part derive from the conventional understanding of infectious diseases as extrinsic risks in driving fast but not slow life history (LH) and related disease control efforts (Lu et al., 2021a, b). The purpose of the present study is to provide a different LH perspective, whereby we argue that infectious diseases may activate slow or fast $\mathrm{LH}$ strategies and elicit laborious or languorous disease-control behavior, depending on the present or past disease fatality that potentially affects intrinsic mortality and vitality state. We conducted an empirical test of our theorization based on a random online sample of 662 adult individuals representing all 32 provinces and administrative regions of mainland China.

\section{LH Tradeoff Strategies}

LH can be defined as the process of organisms capturing energy from their environments to develop themselves and 
to produce and develop offspring (Chang et al., 2019a, b; Ellison, 2017). The timing and pace by which to conduct these two life activities, development and reproduction, depend on the obstacles animals encounter from the environments in acquiring food and safety and turning them into energy. Broadly defined as environmental harshness and unpredictability (Ellis et al., 2009) or simply as environmental adversities (Chang et al., 2019a, b), these obstacles or constraints hinder the acquisition of food or resources and safety that are essential for life (Chang \& $\mathrm{Lu}, 2018)$. When resources are unstable or safety threats are high and uncontrollable, evolution has shaped animals to accelerate development and increase reproductive effort as a way to outgrow the uncontrollable environmental adversities. When the environmental risks concerning food and safety are low or controllable, animals take a slow pace to more fully develop themselves and their offspring. Because of the dynamics of environmental harshness and unpredictability, LH represents constant tradeoffs between development and reproduction in the allocation of energy that is insufficient to fully satisfy both sets of life demands. These two paces of life are referred to as fast vs. slow LH tradeoff strategies (Ellis et al., 2009; Figueredo et al., 2006; Lu \& Chang, 2019; Stearns, 1992). When environments are harsh or unpredictable, animals opt for a fast $\mathrm{LH}$ strategy characterized by an energetic allocation tradeoff for faster development, earlier and greater mating effort, and having more numerous offspring with less parental investment. When the living environment is relatively safe and stable, animals adopt a slow LH strategy by having delayed reproduction and allocating more energy to growth and development, including, especially for human animals, the accumulation of resources, knowledge, and skills that are subsequently converted into higher energy-capturing abilities and parental investment for raising offspring who are fewer in quantity and higher in quality (Chang et al., 2019a, b; Ellis et al., 2009; Stearns et al., 2008).

\section{Intrinsic vs. Extrinsic Mortality and LH Strategies}

A fundamental part of life history theory is the distinction between the intrinsic and extrinsic components of mortality and morbidity and the distinction between these two sources of threats that lead to an organism's eventual demise (Williams, 1957). The intrinsic part refers to functional degradation and causes of it stemming from an organism's internal systems (physical and mental functions). Aging, senescence, and degenerative diseases such as heart problems or diabetes and inflammation are examples of intrinsic mortality and morbidity. Living habits and tear and wear of the body and mind are examples of intrinsic mortality risks (Carnes et al., 2006). Extrinsic mortality and morbidity are death and disability imposed on an organism by extrinsic and mostly uncontrollable risks (e.g., predation, accidents, and infectious diseases) that are insensitive to the organism's internal state of vitality. Although having their separate origins, these two components are intertwined in causing mortality and morbidity (Carnes et al., 2006; Koopman et al., 2015). For example, as an extrinsic mortality threat, lower socioeconomic status causes poor health, as well as bad health habit that, as an intrinsic mortality threat, also causes poor health (Pepper \& Nettle, 2014). Experiment on red grouse (Lagopus lagopus scoticus) shows the intertwining from the other way around, where increased testosterone suppresses immunocompetence of the animal, activating the intrinsic mortality-morbidity process, but it also increases parasite load and thus activates the extrinsic process (Seivwright et al., 2005). The interplay between intrinsic and extrinsic mortality risks suggests that animals potentially respond to both the internal state and the external environment in forming LH strategies (e.g., Chang et al., 2019a, b; Ellis et al., 2021; Nettle et al., 2013). Also known as internal and external predictive adaptive response (Gluckman et al., 2005), this line of research carries an important implication which is that a harsh and unpredictable environment may or may not lead to fast LH depending on the intrinsic mortality or viability conditions.

There is ample evidence supporting this contention. In the red grouse experiments, for example, increased parasite load (extrinsic mortality risk) caused slower but not faster LH response as the birds showed reduced aggression during the subsequent territorial contests (Fox \& Hudson, 2001; Mougeot et al., 2005). As another example, hen flea (Ceratophyllus gallinae) infestation is behaviorally controlled by great tits (Parus major) by waiting for the adult hen flees to vacate the infested nests. The waiting delays the birds' egg laying and hatching by 11 days (Oppliger et al., 1994), making it a good example of disease preventive efforts slowing down LH. Most other animals in their sound intrinsic conditions take prophylactic (e.g., nest cleaning and fumigation, Bush \& Clayton, 2018) and therapeutic actions (e.g., applying antibacterial plants, Hart \& Hart, 2018; Villalba et al., 2014), and the intensity of these disease control efforts increases as a function of the pathogenic severity (Hart, 2011) until when and if the disease becomes so severe that animals capitulate their disease control effort and succumb to the disease which then has the effect of changing the intrinsic vitality state. Animals subsequently respond with fast LH strategies by speeding up rather than slowing down life to outgrow rather than outlive or control the disease. For example, when infected with severe picornavirus, the common fruit fly (Drosophila melanogaster) has a faster development time from egg to adult (GomarizZilber \& Thomas-Orillard, 1993). Similarly, marine snails 
(Cerithidea californica) mature faster when invaded by deadly Trematoda parasites (Lafferty, 1993), and precocial breeding increases among young female Tasmanian devils (Sarcophilus harrisii) suffering from facial cancer that is fatal (Jones et al., 2008). Even more compelling evidence comes from experimental studies where animals exposed to high dosage of infection exhibited high mating behavior, whereas those exposed to lower dosages showed low mating and other slower LH manifestations (e.g., Copeland \& Fedorka, 2012; Hendry et al., 2016; Marzal et al., 2008; Polak \& Starmer, 1998).

These non-human examples show that infectious diseases are associated with both slow and fast LH strategies depending on the severity of the diseases. Similar human evidence may be discerned from the ongoing fight against the COVID19 pandemic. A survey based on 3610 respondents found that the more infectious people believed coronavirus to be, the less willing they were to take behavioral control measures such as social distancing (Akesson et al., 2020). Similarly, associating coronavirus with death (Jimenez et al., 2020) or perceiving it as uncontrollable (Shahnazi et al., 2020) was related to lacking the intention to take preventive actions, whereas perceiving it as controllable was associated with willingness to make disease control efforts. Similarly, in daily life, people normally fight diseases with every means when there is a cure, while slowing down or temporarily stopping other life activities. When fatality rate is high as is the case with a terminal illness, compared to the healthy population, people living with cancer, HIV, and other incurable medical conditions are more likely to engage in promiscuous and risky sexual behaviors and other risky behaviors such as smoking and substance abuse (Bing et al., 2001; Chhatre et al., 2014; Gregoire et al., 2020; Miauton et al., 2003; Nylander et al., 2014; Suris \& Parera, 2005), all of which are faster LH manifestations. Thus, both human and nonhuman evidence are aligned with our theorizing that the relation between infectious disease and LH strategies may differ in direction depending on whether infectious diseases threaten intrinsic vitality. The aligned LH strategy in turn is associated with disease control effort and behavior, with slower LH strategy facilitating and with faster LH strategy inhibiting disease control endeavors.

The above evidence is derived from observations at the individual level. Group-level research examining crossnation and cross-state covariations and multilevel research examining group-level disease prevalence in relation to individual-level LH manifestations yield similar bi-directional findings, equally supportive of our postulation. For example, parasite load and pathogen prevalence were negatively associated with slow LH strategies (e.g., life expectancy, social equality, political freedom, and democratization; moral foundation concerning ingroup affiliation and loyalty [Figueredo et al., 2021, 2017a; Thornhill et al., 2009;
Van Leeuwen et al., 2014]) as well as positively associated with slow LH strategies (e.g., family ties and prosociality; vigilant disease control behavior; restricted sociosexual orientation; moral foundation concerning ingroup affiliation and loyalty [Fincher \& Thornhill, 2012]). These mixed or opposite findings suggest potentially a bi-directional relation between disease prevalence and slow LH possibly as a function of disease severity. The ongoing fight against the COVID-19 pandemic provides another convincing example. In countries and regions where the pandemic has since been proven relatively well controlled (e.g., China has 96,546 infected cases and 4,636 fatalities at the time of manuscript submission, representing group level disease prevalence and fatality), representing slow LH strategies, individuals seemed to have complied with the COVID control measures willingly and vigilantly (e.g., Burki, 2020; Rupiva, 2020; Shaw et al., 2020; Wadvalla, 2020). In contrast, countries and populations that have among the highest infections and fatalities (e.g., United States has 45,791,462 infected cases and 744,541deaths) did not appear to be as prompt or restrictive in implementing and complying with the behavioral control measures especially during the early stages (Betsch, 2020; Sanchez, 2020; Shokoohi et al., 2020; Ward, 2020), but inattention and recklessness that are characteristic of fast $\mathrm{LH}$ continued throughout the pandemic (e.g., Bernton, 2021; Mervosh, 2021). In this case, the extent to which serious disease control effort is exerted by the citizens is apparently contingent on the actual or perceived severity of the pandemic.

\section{Present Study}

Thus, both human and nonhuman evidence from the individualor group-level observations are aligned with our theorizing that infectious disease is potentially bi-directionally related with LH strategies depending on whether infectious diseases threaten intrinsic vitality. The aligned LH strategy in turn is associated with disease control effort and behavior, with slower LH strategy facilitating and with faster LH strategy inhibiting disease control behavior. As shown in these examples, the contingent point to shift between the two LH directions is likely the actual or perceived severity and fatality of the infectious diseases (Duffield et al., 2017). In the present study, we tested the theorization based on a sample of 662 adult residents drawn from all 32 provinces and administrative regions of mainland China. We obtained prevalence and fatality of infectious diseases at the provincial level and slow LH strategies and COVID-19 control behavior at the individual level. We tested the hypothesis that provincial infectious disease fatality moderated the association between provincial prevalence of infectious diseases and individual LH strategy so that, at a lower level of disease fatality, disease prevalence was positively associated 
with slow LH and, at a higher fatality level, disease prevalence was negatively correlated with slow LH strategy. We predicted the same moderating effect of fatality of infectious diseases on the relation between prevalence of infectious diseases and COVID-19 behavioral control. We also hypothesized a positive association between slow LH strategy and COVID-19 behavioral control.

\section{Method}

\section{Sample}

We took a random sample of 662 adults (46.53\% males) aged between 18 and $65(\mathrm{M}=30.69, \mathrm{SD}=7.92)$ from all 32 provinces, administrative regions, and direct municipalities of mainland China, with a subsample size, approximately proportional to the provincial population size, ranging from 13 (Ningxia Hui autonomous administrative region) to 48 (Jiangsu province). The sample was taken by a paid survey website, WJX (https://www.wjx.cn), which administered the questionnaires online in June 2020.

\section{Measures}

\section{Prevalence of Infectious Diseases}

Prevalence of infectious diseases is the total number of cases of infectious diseases in a given statistical population (province, administrative region, or direct municipality) at a given time (we used the year 2003) divided by the number of individuals in that population and multiplied by 100,000 (National Health Commission of China, 2004).

\section{Fatality of Infectious Diseases}

Fatality of infectious diseases is the total number of deaths from infectious diseases in a given statistical population (province, administrative region, or direct municipality) at a given time (the year 2003) divided by the number of individuals in that population (National Health Commission of China, 2004).

We obtained these two measures for each of the 32 provinces, administrative regions, and direct municipalities for the year 2003 which is the earliest year the data are available to the public.

\section{Slow LH Strategy}

The Arizona Life History Battery (ALHB, Figueredo et al., 2007) was adopted and adapted from existing psychological instruments to measure LH strategies. The mini-K is a 20 -item scale that has captured the meaning of ALHB to measure behavioral and cognitive aspects of LH strategies on a single continuum in the direction of slow LH (Figueredo et al., 2007, 2017b ). Sample items include "twhile growing up, I had a close and warm relationship with my biological father," "I try to understand how I got into a situation to figure out how to handle it," and "I would rather have one than several sexual relationships at a time." In the present study, the 20 items were measured on a 7-point scale ranging from 1 (strongly disagree) to 7 (strongly agree). The internal consistency reliability estimate was 0.84 .

\section{COVID-19 Behavioral Control}

Following the WHO recommendations (https://www.who. int/emergencies/diseases/novel-coronavirus-2019/advicefor-public) and the literature (Zhu et al., 2021), we asked participants on a 4-point scale ranging from 1 (seldom) to 4 (always) how frequently they took the COVID control measures in the past two weeks with respect to "wearing face masks when going out," "washing hands with soap," "wearing gloves when shopping," and "avoiding face-to-face interactions with people outside of the household." We also asked participants on a 4-point scale ranging from 1 (once a week or fewer) to 4 (multiple times a day) how frequently in the past two weeks they checked the information regarding "news about the spread of the COVID-19" and "preventive measures and medical treatments of the COVID-19." These six items formed a single factor with an internal consistency reliability estimate of 0.75 .

\section{Results}

Table 1 contains the means, standard deviations, and zeroorder correlations of the variables used in the study. We also examined potential gender differences. Women $(M=3.28$, $\mathrm{SD}=0.64$ ) scored slightly higher on the COVID-19 behavioral control measure than men $(\mathrm{M}=3.17 \mathrm{SD}=0.74 ; t=2.04$, $p=0.04)$. There were no gender differences with other variables.

We conducted hierarchical linear modeling or multilevel analysis (Raudenbush \& Bryk, 2002) using $M$-plus (Muthén \& Muthén, 2012) to test the hypotheses. First, the regression of COVID-19 behavioral control on slow LH strategy was positive and robust as expected $(\beta=0.31$, standard error [s.e.] $=0.036, p<0.001)$. We also regressed slow LH strategy and COVID-19 behavioral control, respectively, on the prevalence of infectious disease. The regression coefficients were not significant as expected $(\beta=0.16$, s.e. $=2.26, p=0.31$ for slow $\mathrm{LH}$ strategy and $\beta=0.11$, s.e. $=0.262, p=0.68$ for COVID-19 
Table 1 Means, standard deviations, and correlations of variables used in the study

\begin{tabular}{lclcc}
\hline & $\begin{array}{l}\text { Prevalence of } \\
\text { infectious } \\
\text { diseases }\end{array}$ & $\begin{array}{l}\text { Fatality of } \\
\text { infectious } \\
\text { diseases }\end{array}$ & Slow LH strategy & $\begin{array}{l}\text { COVID-19 } \\
\text { behavioral } \\
\text { control }\end{array}$ \\
\hline Prevalence of infectious diseases & - & & & \\
Fatality of infectious diseases & $0.30^{* * *}$ & - & - & \\
Slow LH strategy & -0.02 & -0.03 & $0.33^{* * *}$ & - \\
COVID-19 behavioral control & 0.01 & -0.01 & 5.27 & 3.24 \\
Mean & 218.71 & 0.67 & 0.66 & 0.68 \\
SD & 75.72 & 0.56 & \\
\hline
\end{tabular}

behavioral control), but the variance of the two regression coefficients was significant $(\tau=0.008$, s.e. $=0.003$, $p=0.014$ for slow LH; $\tau=0.046$, s.e. $=0.022, p=0.039$ for COVID control), warranting our hypothesized prediction by fatality of infectious disease. We then used the fatality of infectious disease as the predictor to predict the two regression coefficients. The residual variance was greatly reduced (for slow LH, residual $\tau=0.0057$, s.e. $=0.0029, p=0.046$, variance explained $=28.75 \%$; for COVID control, residual $\tau=0.032$, s.e. $=0.025, p=0.21$, variance explained $=30.43 \%$ ). The two regression coefficients were significant as expected. Fatality of infectious disease $(\beta=-0.17$, s.e. $=0.0157, p=0.008)$ negatively predicted the positive regression of slow LH strategy on the prevalence of infectious disease $(\beta=0.16)$, meaning that with one unit increase in fatality of infectious disease, the regression of slow LH strategy on the prevalence of infectious disease was attenuated by -0.17 . That is, higher fatality of infectious diseases weakened the positive association between prevalence of infectious disease and slow LH strategy. Similarly, fatality of infectious disease $(\beta=-0.26$, s.e. $=0.122, \mathrm{p}=0.035)$ was negatively associated with the positive regression of COVID-19 behavioral control on prevalence of infectious disease $(\beta=0.11)$. The result suggests that higher levels of mortality of infectious disease attenuated the positive association between prevalence of infectious disease and COVID-19 behavioral control. Specifically, the regression of COVID-19 behavioral control on the prevalence of infectious disease attenuated by 0.26 units with one unit increase in fatality of infectious disease. For each of these two regressions, Fig. 1 plots a pair of simple slopes at +1 SD and 1 SD of fatality of infectious disease. For both associations of the prevalence of infectious disease to slow LH strategy and to COVID-19 behavioral control, the association or simple slope was positive at lower levels (1 SD) and was negative at higher levels (+1 SD) of fatality of infectious disease (Fig. 2). These results support our hypotheses.

\section{Discussion}

The COVID-19 pandemic has caught the world by surprise. However, it is but one of many instances of environmental adversities that have recurred in evolutionary history. Such adversities have resulted in animals evolving coping

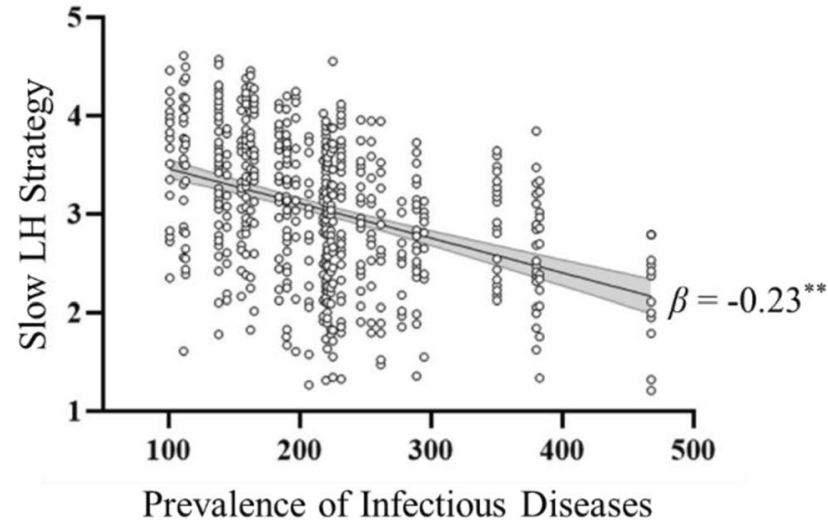

A

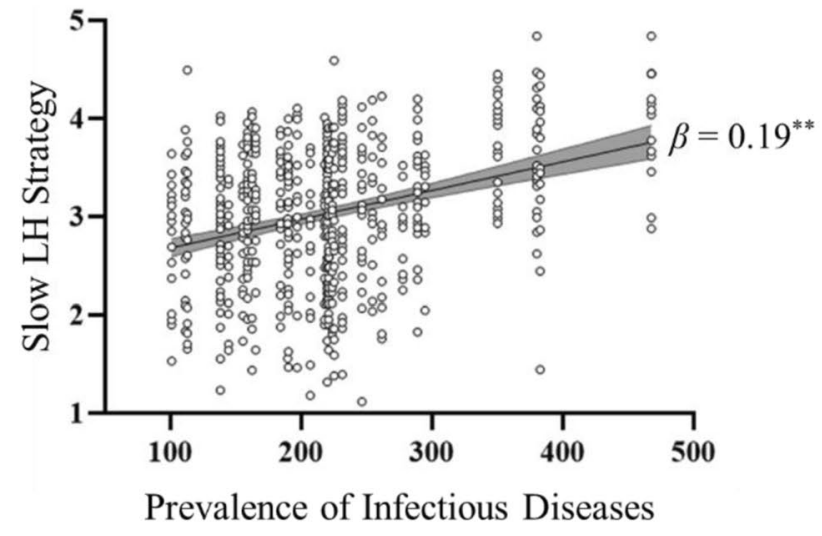

B

Fig. 1 Simple slopes and 95\% confidence bands of regression of slow LH strategy on the prevalence of infectious diseases at 1 SD above (A) and 1 SD below $(\mathbf{B})$ the mean of fatality of infectious diseases 


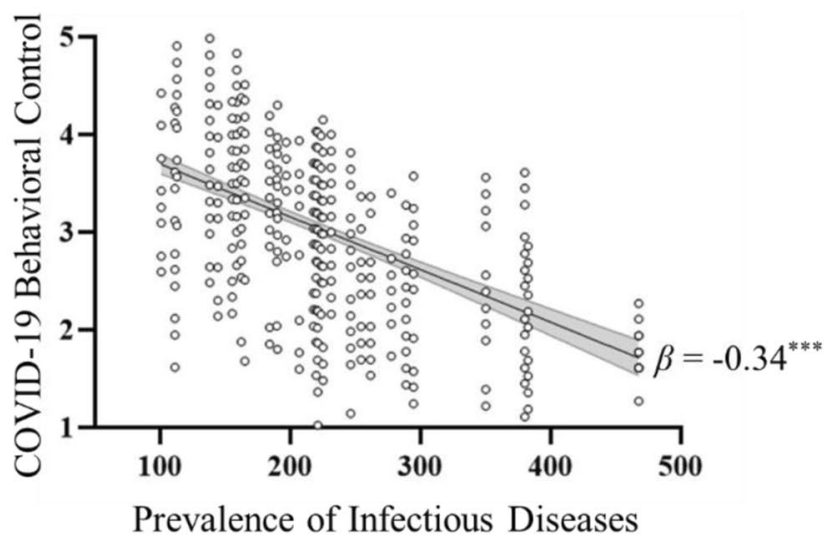

A

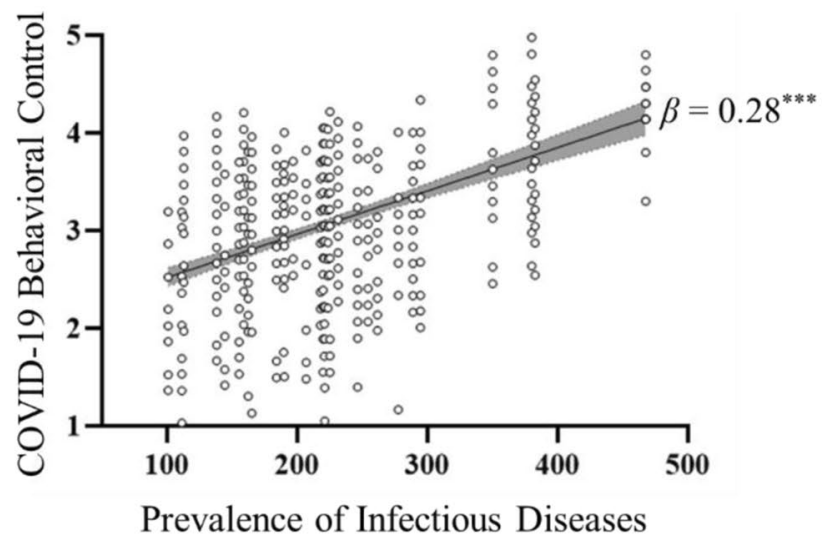

B

Fig. 2 Simple slopes and 95\% confidence bands of regression of COVID-19 behavioral control on the prevalence of infectious diseases at 1 SD above (A) and 1 SD below (B) the mean of fatality of infectious diseases

strategies to deal with similar safety issues of the present living environments such as the ongoing COVID-19 pandemic. As shown by the findings of the present study, individuals' coping with COVID-19 is aligned with their LH strategies, with an industrious and vigilant disease control effort being associated with the slower end of LH strategies, and a languorous and lackadaisical involvement with the faster end. Individuals' disease coping and LH strategies are both shaped by a combination of prevalence and fatality of infectious diseases in the community. In regions where infectious diseases were relatively severe as indicated by higher fatality rates, the prevalence of infectious diseases was negatively associated with slower LH strategies and was negatively associated with disease control efforts in coping with COVID-19. In regions where fatality rate was relatively low, the prevalence of infectious diseases positively predicted both slower LH strategies and more active COVID control efforts. An important LH exposition of the findings is that disease prevalence does not form individuals' $\mathrm{LH}$ strategies or influence individuals' current disease control effort in one direction. Instead, its effect is contingent on the severity of infectious diseases in the region.

This theoretical implication may not be human specific either but can be corroborated by observations with other animals. Most animals in their sound physical conditions take prophylactic and therapeutic actions to fight diseases when they are controllable. They clean, sanitize, and fumigate their residences (Bush \& Clayton, 2018). They socially distance themselves from and peripheralize sick conspecifics (Behringer et al., 2006; Hart, 2011). They also reinforce behavioral immunity and body maintenance by increasing preening and grooming and sun and water bathing (Villalba et al., 2014); by applying antibacterial plants both externally and internally (Hart \& Hart, 2018); and by adopting an overall behavioral style that is risk-averse, cautious, and vigilant (Barber \& Dingemanse, 2010; Kortet et al., 2010). These behaviors all constitute slow LH strategies. When deadly parasites and viruses such as cancer (e.g., Jones et al., 2008) have terminally infected the animals, they engage in faster LH strategies by not slowing down to take disease control efforts but maturing and reproducing more quickly (e.g., Gomariz-Zilber \& Thomas-Orillard, 1993). Animals also manifest increasing faster $\mathrm{LH}$ as direct functions of increased disease severity (e.g., Marzal et al., 2008). These observations with other animals and our findings of humans together challenge the conceptualization that infectious diseases function as extrinsic risks in uniformly driving fast or faster LH (e.g., Ellis et al., 2009). Infectious diseases may function as intrinsic risks that shape slower LH and may function as extrinsic risks to result in faster LH depending on the severity and controllability of the diseases. Most animals try to fight a disease when they can, while slowing down other aspects of life (Hart, 2011), and succumb to it and accelerate LH when the disease is out of control (Duffield et al., 2017).

The above explanation about extrinsic risks is especially relevant for humans. Most extrinsic risks that cause fast $\mathrm{LH}$ in other animals by inflicting indiscriminate and uncontrollable casualties on the adult population may have ceased to have the same sweeping effect on humans because humans have long conquered nature (Alexander, 1990) and because intraspecific competition that has become the principal selection pressure for human brain evolution (Alexander, 1990) creates massive human individual differences unlike other animals (Nettle, 2006). In much of human evolution, extrinsic risks from nature are therefore rendered controllable that do not affect the entire adult population uniformly but are resolvable depending on individual abilities and 
competitiveness. Solving these otherwise unsolvable extrinsic challenges characterizes human slow LH evolution and results in and is the result of human brain enlargement that by itself represents one of the slowest LH traits and tradeoffs. Moreover, exponential encephalon development enables extended slow LH phenotypes (Dawkins, 1989) that far exceed biobehavioral undertaking in rendering extrinsic risks controllable and accelerating human slow LH. In the risk domain of infectious diseases, for example, humans have throughout history deployed elaborate and sophisticated external disease control measures. These external measures are extended slow LH phenotypes. They range from various therapeutic and interventional methods constituting traditional herbal medicine, which is present in almost all ancestral human groups (e.g., Petrovska, 2012; Sneader, 2005) to the development and deployment of modern medicine and public health infrastructures. Throughout human history, these external risk protections are not equally available to all individuals and therefore create additional individual differences in risk vulnerability (e.g., disease susceptibility), risk controllability (e.g., disease resistance), and, as shown by the present findings, in tackling risks (e.g., behavioral control of COVID-19). Because of these acquired individual differences of the human adult population, infectious diseases and most other environmental risks may not be singularly defined as extrinsic to cause invariant casualties and to illicit invariant responses.

The present study has limitations or potential controversies especially concerning the psychometric approach we took and the mini-K scale we used in conceptualizing and measuring LH strategies. LH research in psychology has been criticized for attempting to measure within-species LH trait variations (Stearns \& Rodrigues, 2020; Zietsch \& Sidari, 2020) in part because the theoretical framework of LH research is derived from between-species, higher taxonomic observations in biology. The mini- $\mathrm{K}$ is meant to measure cognitive and behavioral aspects of LH strategies (Figueredo et al., 2017b), which is therefore narrower in meaning than similar constructs derived from cross-species observations. However, mini-K is the most widely used instrument to measure human LH strategies, and its cognitive focus is not necessarily a limitation in our study because our research is not about physiological but is about behavioral immunity and disease control that involve primarily cognitive and behavioral systems not only for humans but for all animals. There is also recognition of $\mathrm{LH}$ variations between individuals (Woodley of Menie et al., 2021) and a growing literature that uses the psychometric approach to study these individual variations. This approach should offer a new direction into which to expand methodologically, theoretically, and multi-disciplinarily the traditional unidimensional biological LH research. Another related limitation or delimitation is that we did not examine the internal state (e.g., participants' health status), together with the external environment (e.g., prevalence of infectious diseases), in precipitating LH strategies. Nor did we examine the physiological (e.g., physical immune systems), together with behavioral disease control, in response to the COVID-19 pandemic. Future research could add the physiological consideration both as input and as an output of LH strategies. Despite these and other limitations, the present study contributes to the literature by developing and empirically testing a different LH perspective: Infectious diseases, specifically, and environmental adversities, in general, are not unidirectionally related with LH strategies but, depending on the severity of the underlying threat, manifest either as intrinsic or extrinsic mortality process in enacting either slow or fast $\mathrm{LH}$ and the related behavior.

Author Contribution Hui Jing Lu and Lei Chang conceptualized and wrote the manuscript; Xin Rui Wang and Yuan Yuan Liu analyzed and collected the data; all authors reviewed the manuscript.

Funding This work was supported by the Research Grants Council of the Hong Kong Special Administrative Region (grant number 15608415) and the University of Macau (grant number MYRG2018-00100-FSS).

Availability of Data and Material The data that support the findings of this study are openly available in Open Science Framework at http:// doi.org/10.17605/OSF.IO/UR5XM.

\section{Declarations}

Ethics Approval Ethics approval was obtained from the Ethics Committee of the University of Macau (Reference number: 2018-25).

Consent to Participate Informed consent was obtained from all individual participants included in the study.

Consent for Publication The participant has consented to the submission with no identifying information to publication.

Conflict of Interest The authors declare no competing interests.

Human and Animal Rights and Informed Consent The study has been approved by the appropriate ethics committee and has therefore been performed in accordance with the ethical standards laid down in the 1975 Declaration of Helsinki and its later amendments.

\section{References}

Akesson, J., Ashworth-Hayes, S., Hahn, R., Metcalfe, R. D., \& Rasooly, I. (2020). Fatalism, beliefs, and behaviors during the COVID-19 pandemic (No. w27245). National Bureau of Economic Research. https://doi.org/10.3386/w27245

Alexander, R. D. (1990). How did humans evolve? reflections on the uniquely unique species. Museum of Zoology Special Publication No. 1. 1-38. Ann Arbor: The University of Michigan.

Anderson, R. M., Heesterbeek, H., Klinkenberg, D., \& Hollingsworth, T. D. (2020). How will country-based mitigation measures influence the course of the COVID-19 epidemic? The Lancet, 395, 931-934. https://doi.org/10.1016/S0140-6736(20)30567-5 
Barber, I., \& Dingemanse, N. J. (2010). Parasitism and the evolutionary ecology of animal personality. Philosophical Transactions of the Royal Society B: Biological Sciences, 365(1560), 4077-4088. https://doi.org/10.1098/rstb.2010.0182

Behringer, D. C., Butler, M. J., \& Shields, J. D. (2006). Avoidance of disease by social lobsters. Nature, 441(7092), 421-421. https:// doi.org/10.1038/441421a

Bernton, H. (2021). Restaurants defy COVID-19 restrictions in uprising embraced by Northwest far-right groups. Seattle Times.

Betsch, C. (2020). How behavioural science data helps mitigate the COVID-19 crisis. Nature Human Behavior, 4, 438-438. https:// doi.org/10.1038/s41562-020-0866-1

Bing, E. G., Burnam, A., Longshore, D., Fleishman, J. A., Sherbourne, C. D., London, A. S., Turner, B. J., Eggan, F., Beckman, R., Vitiello, B., Morton, S. C., Orlando, M., Bozzette, S. A., OrtizBarron, L., \& Shapiro, M. (2001). Psychiatric disorders and drug use among human immunodeficiency virus-infected adults in the United States. Archives of General Psychiatry, 58(8), 721-728. https://doi.org/10.1001/archpsyc.58.8.721

Burki, T. (2020). China's successful control of COVID-19. The Lancet Infectious Diseases, 20(11), 1240-1241. https://doi.org/10.1016/ S1473-3099(20)30800-8

Bush, S. E., \& Clayton, D. H. (2018). Anti-parasite behaviour of birds. Philosophical Transactions of the Royal Society B, 373(1751), 20170196. https://doi.org/10.1098/rstb.2017.0196

Carnes, B. A., Holden, L. R., Olshansky, S. J., Witten, M. T., \& Siegel, J. S. (2006). Mortality partitions and their relevance to research on senescence. Biogerontology, 7, 183-198.

Chang, L., \& Lu, H. J. (2018). Resource and extrinsic risk in defining fast life histories of rural Chinese left-behind children. Evolution and Human Behavior, 39, 59-66. https://doi.org/10.1016/j. evolhumbehav.2017.10.003

Chang, L., Lu, H. J., Lansford, J. E., Bornstein, M. H., Steinberg, L., Chen, B., Skinner, A. T., Dodge, K. A., Deater-Deckard, K., Bacchini, D., Pastorelli, C., Alampay, L. P., Tapanya, S., Sorbring, E., Oburu, P., Al-Hassan, S., Di Giunta, L., Malone, P. S., Uribe Tirado, L. M., \& Yotanyamaneewong, S. (2019a). External environment and internal state in relation to life history behavioral profiles of adolescents in nine countries. Proceedings of the Royal Society B: Biological Sciences, 286(1917), 20192097. https://doi.org/10.1098/rspb.2019.2097

Chang, L., Lu, H. J., Lansford, J. E., Skinner, A. T., Bornstein, M. H., Steinberg, L., Dodge, K., Chen, B. B., Tian, Q., Bacchini, D., Deater-Deckard, K., Pastorelli, C., Alampay, L. P., Sorbring, E., Al-Hassan, S. M., Oburu, P., Malone, P. S., Di Giunta, L., Uribe Tirado, L. M., \& Tapanya, S. (2019b). Environmental harshness and unpredictability, life history, and social and academic behavior of adolescents in nine countries. Developmental Psychology, $55,890-903$.

Chhatre, S., Metzger, D. S., Malkowicz, S. B., Woody, G., \& Jayadevappa, R. (2014). Substance use disorder and its effects on outcomes in men with advanced-stage prostate cancer. Cancer, 120(21), 3338-3345. https://doi.org/10.1002/cncr.28861

Conti, A., \& Gensini, G. F. (2007). The historical evolution of some intrinsic dimensions of quarantine. Journal of History of Medicine, 19(1), 173-188. https://doi.org/10.1002/cncr.28861

Copeland, E. K., \& Fedorka, K. M. (2012). The influence of male age and simulated pathogenic infection on producing a dishonest sexual signal. Proceedings of Royal Society B: Biological Sciences, 279, 4740-4746. https://doi.org/10.1098/rspb.2012.1914

Dawkins, R. (1989). The extended phenotype. Oxford University Press.

Duffield, K. R., Bowers, E. K., Sakaluk, S. K., \& Sadd, B. M. (2017). A dynamic threshold model for terminal investment. Behavioral Ecology and Sociobiology, 71(12), 1-17. https://doi.org/10.1007/ s00265-017-2416-z
Ellis, B. J., Shakiba, N., Adkins, D. E., \& Lester, B. M. (2021). Early external-environmental and internal-health predictors of risky sexual and aggressive behavior in adolescence: An integrative approach. Developmental Psychobiology, 63, 556-571.

Ellis, B. J., Figueredo, A. J., Brumbach, B. H., \& Schlomer, G. L. (2009). Fundamental dimensions of environmental risk. Human Nature, 20(2), 204-268. https://doi.org/10.1007/ s12110-009-9063-7

Ellison, P. T. (2017). Endocrinology, energetics, and human life history: A synthetic model. Hormones and Behavior, 91, 97-106. https:// doi.org/10.1016/j.yhbeh.2016.09.006

Figueredo, A. J., Hertler, S. C., \& Peñaherrera-Aguirre, M. (2021). The biogeography of human diversity in life history strategy. Evolutionary Behavioral Sciences, 15(1), 10.

Figueredo, A. J., de Baca, T. C., Fernandes, H. B. F., Black, C. J., Peñaherrera, M., Hertler, S., \& Meisenberg, G. (2017a). A sequential canonical cascade model of social biogeography: Plants, parasites, and people. Evolutionary Psychological Science, 3(1), 40-61.

Figueredo, A. J., Garcia, R. A., Menke, J. M., Jacobs, W. J., Gladden, P. R., Bianchi, J., \& Jiang, Y. (2017b). The K-SF-42: A new short form of the Arizona Life History Battery. Evolutionary Psychology, 15, 1474704916676276. https://doi.org/10.1016/j.paid.2005. 06.009

Figueredo, A. J., Vásquez, G., Brumbach, B. H., \& Schneider, S. M. (2007). The K-factor, covitality, and personality. Human Nature, 18, 47-73. https://doi.org/10.1007/BF02820846

Figueredo, A. J., Vásquez, G., Brumbach, B. H., Schneider, S. M., Sefcek, J. A., Tal, I. R., \& Jacobs, W. J. (2006). Consilience and life history theory: From genes to brain to reproductive strategy. Developmental Review, 26, 243-275. https://doi.org/10.1016/j.dr. 2006.02.002

Fincher, C. L., \& Thornhill, R. (2012). Parasite-stress promotes ingroup assortative sociality: The cases of strong family ties and heightened religiosity. Behavioral and Brain Sciences, 35(2), 61-79.

Fox, A., \& Hudson, P. J. (2001). Parasites reduce territorial behaviour in red grouse (lagopus lagopus scoticus). Ecology Letters, 4(2), 139-143. https://doi.org/10.1046/j.1461-0248.2001.00207.x

Gluckman, P. D., Hanson, M. A., \& Spencer, H. G. (2005). Predictive adaptive responses and human evolution. Trends in Ecology \& Evolution, 20(10), 527-533. https://doi.org/10.1016/j.tree.2005. 08.001

Gomariz-Zilber, E., \& Thomas-Orillard, M. (1993). Drosophila C virus and Drosophila hosts: A good association in various environments. Journal of Evolutionary Biology, 6(5), 677-689. https:// doi.org/10.1046/j.1420-9101.1993.6050677.x

Gregoire, S., Lamore, K., Laurence, V., Moura, D. S., Marec-Berard, P., Leprince, T., Corradini, N., Blin, N., Chauvet, S., Seigneur, E., \& Flahault, C. (2020). Coping strategies and factors related to problematic substance use and behavioral addictions among adolescents and young adults with cancer. Journal of Adolescent and Young Adult Oncology, 9(6), 639-650. https://doi.org/10.1089/ jayao.2019.0171

Hart, B. L. (2011). Behavioural defences in animals against pathogens and parasites: Parallels with the pillars of medicine in humans. Philosophical Transactions of the Royal Society B: Biological Sciences, 366(1583), 3406-3417. https://doi.org/10.1098/rstb. 2011.0092

Hart, B. L., \& Hart, L. A. (2018). How mammals stay healthy in nature: The evolution of behaviours to avoid parasites and pathogens. Philosophical Transactions of the Royal Society B: Biological Sciences, 373(1751), 20170205. https://doi.org/10.1098/rstb.2017. 0205 . 
Hendry, T. A., Clark, K. J., \& Baltrus, D. A. (2016). A highly infective plant-associated bacterium influences reproductive rates in pea aphids. Royal Society Open Science, 3, 150478. https://doi.org/ 10.1098/rsos. 150478

Jimenez, T., Restar, A., Helm, P. J., Cross, R. I., Barath, D., \& Arndt, J. (2020). Fatalism in the context of COVID-19: Perceiving coronavirus as a death sentence predicts reluctance to perform recommended preventive behaviors. SSM-Population Health, 11, 100615. https://doi.org/10.1016/j.ssmph.2020.100615

Jones, M. E., Cockburn, A., Hamede, R., Hawkins, C., Hesterman, H., Lachish, S., \& Pemberton, D. (2008). Life-history change in disease-ravaged Tasmanian devil populations. Proceedings of the National Academy of Sciences, 105(29), 10023-10027. https://doi. org/10.1073/pnas.0711236105

Koopman, J. J., Wensink, M. J., Rozing, M. P., van Bodegom, D., \& Westendorp, R. G. (2015). Intrinsic and extrinsic mortality reunited. Experimental Gerontology, 67, 48-53. https://doi.org/10. 1016/j.exger.2015.04.013

Kortet, R., Hedrick, A. V., \& Vainikka, A. (2010). Parasitism, predation and the evolution of animal personalities. Ecology Letters, 13(12), 1449-1458. https://doi.org/10.1111/j.1461-0248.2010.01536.x

Lafferty, K. D. (1993). The marine snail. Cerithidea californica, matures at smaller sizes where parasitism is high. Oikos, 68(1), 3-3. https://doi.org/10.2307/3545303

Lu, H. J., \& Chang, L. (2019). Aggression and risk taking as adaptive implementations of fast life history strategy. Developmental Sciences, 22, e12827.

Lu, H. J., Liu, Y. Y., \& O, J., Guo, S., Zhu, N., Chen, B. B., Lansford, J., \& Chang, L. (2021a). Disease history and life history predict behavioral control of the COVID-19 pandemic. Evolutionary Psychology. https://doi.org/10.1177/14747049211000714

Lu, H. J., Liu, Y. Y., O, J., Guo, S., Zhu, N., Chen, B. B., Lansford, J. E., \& Chang, L. (2021b). Disease history and life history predict behavioral control of the COVID-19 pandemic. Evolutionary Psychology. https://doi.org/10.1177/14747049211000714

Marzal, A., Bensch, S., Reviriego, M., Balbontin, J., \& de Lope, F. (2008). Effects of malaria double infection in birds: One plus one is not two. Journal of Evolutionary Biology, 21, 979-987. https:// doi.org/10.1111/j.1420-9101.2008.01545.x

Mervosh, S. (2021). Gov. DeSantis of Florida to let parents opt of school masking. New York Times.

Miauton, L., Narring, F., \& Michaud, P. A. (2003). Chronic illness, life style and emotional health in adolescence: Results of a crosssectional survey on the health of 15-20-year-olds in Switzerland. European Journal of Pediatrics, 162(10), 682-689. https://doi. org/10.1007/s00431-003-1179-x

Mougeot, F., Evans, S. A., \& Redpath, S. M. (2005). Interactions between population processes in a cyclic species: Parasites reduce autumn territorial behaviour of male red grouse. Oecologia, 144(2), 289-298. https://doi.org/10.1007/s00442-005-0080-x

Murray, D. R., \& Schaller, M. (2009). Historical prevalence of infectious diseases within 230 geopolitical regions: A tool for investigating origins of culture. Journal of Cross-Cultural Psychology, 41(1), 99-108. https://doi.org/10.1177/0022022109349510

Muthén, L. K., \& Muthén, B. O. (1998-2012). Mplus User's Guide. Seventh Edition. Los Angeles, CA: Muthén \& Muthén.

National Health Commission of China. (2004). China health statistics yearbook. Peking Union Medical College Press.

Nettle, D. (2006). The evolution of personality variation in humans and other animals. American Psychologist, 61, 622-631. https://doi. org/10.1037/0003-066X.61.6.622

Nettle, D., Frankenhuis, W. E., \& Rickard, I. J. (2013). The evolution of predictive adaptive responses in human life history. Proceedings of the Royal Society B: Biological Sciences, 280(1766), 20131343. https://doi.org/10.1098/rspb.2013.1343
Nylander, C., Seidel, C., \& Tindberg, Y. (2014). The triply troubled teenager - chronic conditions associated with fewer protective factors and clustered risk behaviours. Acta Paediatrica, 103(2), 194-200. https://doi.org/10.1111/apa.12461

Oppliger, A., Richner, H., \& Christe, P. (1994). Effect of an ectoparasite on lay date, nest-site choice, desertion, and hatching success in the great tit (Pants major). Behavioral Ecology, 5(2), 130-134. https://doi.org/10.1093/beheco/5.2.130

Pepper, G. V., \& Nettle, D. (2014). Perceived extrinsic mortality risk and reported effort in looking after health. Human Nature, 25, 378-392. https://doi.org/10.1007/s12110-014-9204-5

Petrovska, B. B. (2012). Historical review of medicinal plants' usage. Pharmacognosy Reviews, 6(1), 1-15. https://doi.org/10.4103/ 0973-7847.95849

Polak, M., \& Starmer, W. T. (1998). Parasite-induced risk of mortality elevates reproductive effort in male Drosophila. Proceedings of the Royal Society of London. Series B: Biological Sciences, 265, 2197-2201. https://doi.org/10.1098/rspb.1998.0559

Raudenbush, S. W., \& Bryk, A. S. (2002). Hierarchical linear models: Applications and data analysis methods. Sage.

Rupiva, M. (2020, April 23). At war with Covid-19: Opportunities for Africa? Mail \& Guardian. Retrieved from https://mg.co.za/ article/2020-04-23-at-war-with-covid-19-opportunities-for-africa/

Sanchez, G. H. (2020, March 23). 24 Pictures of Americans failing horribly at social distancing during the Coronavirus outbreak. BuzzFeedNews. https://www.buzzfeednews.com/article/gabrielsanchez/ americans-coronavirus-social-distancing-shelter-in-place

Seivwright, L. J., Redpath, S. M., Mougeot, F., Leckie, F., \& Hudson, P. J. (2005). Interactions between intrinsic and extrinsic mechanisms in a cyclic species: Testosterone increases parasite infection in red grouse. Proceedings of the Royal Society B: Biological Sciences, 272, 2299-2304. https://doi.org/10.1098/rspb.2005.3233

Shahnazi, H., Ahmadi-Livani, M., Pahlavanzadeh, B., Rajabi, A., Hamrah, M. S., \& Charkazi, A. (2020). Assessing preventive health behaviors from COVID-19: A cross sectional study with health belief model in Golestan Province, Northern of Iran. Infectious Diseases of Poverty, 9(1). https://doi.org/10.1186/ s40249-020-00776-2

Shaw, R., Kim, Y. K., \& Hua, J. (2020). Governance, technology and citizen behavior in pandemic: Lessons from COVID-19 in East Asia. Progress in Disaster Science, 6, 100090. https://doi.org/10. 1016/j.pdisas.2020.100090

Shokoohi, M., Osooli, M., \& Stranges, S. (2020). COVID-19 pandemic: What can the West learn from the East. International Journal of Health Policy and Management, 9(10), 436-438. https:// doi.org/10.34172/ijhpm.2020.85

Sneader, W. (2005). Drug discovery: A history. John Wiley \& Sons.

Stearns, S. C. (1992). The evolution of life histories. Oxford University Press.

Stearns, S. C., Allal, N., \& Mace, R. (2008). Life history theory and human development. In C. Crawford \& D. Krebs (Eds.), Foundations of evolutionary psychology (pp. 47-69). Taylor \& Francis Group/Lawrence Erlbaum Associates.

Stearns, S. C., \& Rodrigues, A. M. (2020). On the use of "life history theory" in evolutionary psychology. Evolution and Human Behavior, 41(6), 474-485. https://doi.org/10.1016/j.evolhumbehav.2020. 02.001

Suris, J. C., \& Parera, N. (2005). Sex, drugs and chronic illness: Health behaviours among chronically ill youth. The European Journal of Public Health, 15(5), 484-488. https://doi.org/10.1093/eurpub/ cki001

Syal, K. (2020). COVID-19: Herd immunity and convalescent plasma transfer therapy. Journal of Medical Virology, 92, 1380-1382. https://doi.org/10.1002/jmv.25870 
Thornhill, R., Fincher, C. L., \& Aran, D. (2009). Parasites, democratization, and the liberalization of values across contemporary countries. Biological Reviews, 84(1), 113-131.

Van Leeuwen, F., Koenig, B. L., Graham, J., \& Park, J. H. (2014). Moral concerns across the United States: Associations with lifehistory variables, pathogen prevalence, urbanization, cognitive ability, and social class. Evolution and Human Behavior, 35(6), 464-471.

Villalba, J. J., Miller, J., Ungar, E. D., Landau, S. Y., \& Glendinning, J. (2014). Ruminant self-medication against gastrointestinal nematodes: Evidence, mechanism, and origins. Parasite, 21, 31. https:// doi.org/10.1051/parasite/2014032

Wadvalla, B. A. (2020). Covid-19: Decisive action is the hallmark of South Africa's early success against coronavirus. BMJ, 369, m1623. https://doi.org/10.1136/bmj.m1623

Ward, A. (2020). Anti-lockdown protests aren't just an American thing. They're a global phenomenon. Vox. https://www.vox. com/2020/5/20/21263919/anti-lockdown-protests-coronavirusgermany-brazil-uk-chile
Williams, G. C. (1957). Pleiotropy, natural selection, and the evolution of senescence. Evolution, 11(4), 398-411. https://doi.org/10. $2307 / 2406060$

Woodley of Menie, M.A., Luoto, S., Peñaherrera-Aguirre, M., \& Sarraf, M. A. (2021). Life history is a major source of adaptive individual and species differences: A critical commentary on Zietsch and Sidari (2020). Evolutionary Psychological Science, 7(3), 213-231. https://doi.org/10.1007/s40806-021-00280-2

Zietsch, B. P., \& Sidari, M. J. (2020). A critique of life history approaches to human trait covariation. Evolution and Human Behavior, 41(6), 527-535.

Zhu, N., Smetana, J. G., \& Chang, L. (2021). Acceptance of society-level and individual-level preventive measures during the COVID-19 pandemic among college students in three societies. Journal of Cross-Cultural Psychology, 0022022121995971. https://doi.org/10.1177/0022022121995971

Publisher's Note Springer Nature remains neutral with regard to jurisdictional claims in published maps and institutional affiliations. 